\title{
Antibiofilm and Antivirulence Activities of 6-Gingerol and 6-Shogaol Against Candida albicans Due to Hyphal Inhibition
}

\author{
Jin-Hyung Lee ${ }^{1 \dagger}$, Yong-Guy Kim ${ }^{1 \dagger}$, Pilju Choi ${ }^{2}$, Jungyeob Ham², Jae Gyu Park ${ }^{3 *}$ and \\ Jintae Lee ${ }^{1 *}$ \\ 'School of Chemical Engineering, Yeungnam University, Gyeongsan, South Korea, ${ }^{2}$ Natural Products Research Institute, \\ Korea Institute of Science and Technology, Gangneung, South Korea, ${ }^{3}$ Advanced Bio Convergence Center, Pohang \\ Technopark Foundation, Pohang, South Korea
}

OPEN ACCESS

Edited by:

You-Hee Cho,

CHA University, South Korea

Reviewed by:

Hee-Deung Park,

University of Wisconsin-Madison

United States

Qing-shan Shi,

Guangdong Institute of

Microbiology (CAS), China

*Correspondence:

Jae Gyu Park

jaepark@pohangtp.org

Jintae Lee

jtlee@ynu.ac.kr

†These authors have contributed equally to this work

Received: 07 June 2018 Accepted: 07 August 2018 Published: 28 August 2018

Citation:

Lee J-H, Kim Y-G, Choi P, Ham J,

Park JG and Lee J (2018) Antibiofilm and Antivirulence Activities of

6-Gingerol and 6-Shogaol Against

Candida albicans Due to Hypha

Inhibition.

Front. Cell. Infect. Microbiol. 8:299.

doi: 10.3389/fcimb.2018.00299
Candida albicans is an opportunistic pathogen and responsible for candidiasis. C. albicans readily forms biofilms on various biotic and abiotic surfaces, and these biofilms can cause local and systemic infections. C. albicans biofilms are more resistant than its free yeast to antifungal agents and less affected by host immune responses. Transition of yeast cells to hyphal cells is required for biofilm formation and is believed to be a crucial virulence factor. In this study, six components of ginger were investigated for antibiofilm and antivirulence activities against a fluconazole-resistant $C$. albicans strain. It was found 6-gingerol, 8-gingerol, and 6-shogaol effectively inhibited biofilm formation. In particular, 6-shogaol at $10 \mu \mathrm{g} / \mathrm{ml}$ significantly reduced C. albicans biofilm formation but had no effect on planktonic cell growth. Also, 6-gingerol and 6-shogaol inhibited hyphal growth in embedded colonies and free-living planktonic cells, and prevented cell aggregation. Furthermore, 6-gingerol and 6-shogaol reduced C. albicans virulence in a nematode infection model without causing toxicity at the tested concentrations. Transcriptomic analysis using RNA-seq and qRT-PCR showed 6-gingerol and 6-shogaol induced several transporters (CDR1, CDR2, and RTA3), but repressed the expressions of several hypha/biofilm related genes (ECE1 and HWP1), which supported observed phenotypic changes. These results highlight the antibiofilm and antivirulence activities of the ginger components, 6-gingerol and 6-shogaol, against a drug resistant $C$. albicans strain.

Keywords: antivirulence, biofilm, C. albicans, gingerol, hyphae, shogaol

\section{INTRODUCTION}

Candida albicans is an opportunistic pathogen normally present on skin and mucous membranes, such as, those of the vagina, mouth, and rectum. C. albicans colonizes host tissues and various indwelling medical devices (Ramage et al., 2005; Sardi et al., 2013) and readily develops biofilms on biotic and abiotic surfaces that are intrinsically resistant to conventional antifungal therapeutics and the host immune system (Nobile et al., 2006b). C. albicans can grow as oval budding yeasts, pseudohyphae, or true hyphae. For biofilm development, yeast cells initially attach to a surface, and this is then followed by germ tube formation and hyphal transition, and mature biofilms are typically formed within $24 \mathrm{~h}$ (Nobile et al., 2006b). The transition of yeast cells to hyphal cells 
appears to regulate biofilm maturation, and hyphal transition is considered a crucial virulence factor in Candida infections (Carradori et al., 2016). Also, many clinical isolates of C. albicans exhibit drug resistance against commercial antifungals, such as, azoles and polyenes, which are used to treat candidiasis (Tobudic et al., 2010; Taff et al., 2013; Sandai et al., 2016). Hence, novel antivirulence drugs not prone to the development of antifungal resistance, are required to eradicate C. albicans biofilms and virulence.

Phytochemicals are important sources for antimicrobial and antibiofilm agents against drug resistant microorganisms (Nascimento et al., 2000). Recently, several studies have demonstrated ginger components have antibiofilm activities against pathogenic bacteria, such as, ginger water extract against Pseudomonas aeruginosa (Kim and Park, 2013) and against Salmonella Typhimurium and Escherichia coli (Khiralla, 2015), and zingerone (Kumar et al., 2013), raffinose (Kim et al., 2016a), 6-gingerol (Kim et al., 2015), and 6- and 8-gingerol analogs (Choi et al., 2017) against $P$. aeruginosa. However, the antibiofilm activities of ginger components have not been studied in any yeast species.

In this study, the antibiofilm activities of six ginger components, namely, 6-gingerol, 8-gingerol, 10-gingerol, 6shogaol, 8-shogaol, and 10-shogaol, were initially investigated against antifungal-resistant $C$. albicans strain. Two active compounds 6-gingerol and 6-shogaol were further evaluated with respect to hyphal and virulence inhibition. Scanning electron microscopy (SEM) and confocal laser scanning microscopy (CLSM) were used to investigate the effects of 6-gingerol and 6shogaol on morphological changes, biofilm formation, and on the hyphal growth of $C$. albicans. The molecular basis of the alterations in C. albicans physiology upon exposure to 6-gingerol and 6-shogaol was also investigated using RNA-seq and qRTPCR. In addition, an in vivo Caenorhabditis elegans model was used to confirm the antivirulence efficacies of 6-gingerol and 6-shogaol. This is the first report to be issued regarding the use of 6-gingerol or 6-shogaol to inhibit C. albicans biofilm formation and hyphal formation and to reduce the virulence of this pathogen.

\section{MATERIALS AND METHODS}

\section{Strains and Medium}

In this study, we used fluconazole resistant C. albicans strain DAY185 (minimum inhibitory concentration $>1,024 \mu \mathrm{g} / \mathrm{ml}$ ). C. albicans was maintained in potato dextrose agar (PDA) or potato dextrose broth (PDB). The gingerols and shogaols (6gingerol, 8-gingerol, 10-gingerol, 6-shogaol, 8-shogaol, and 10shogaol) used in this study were purchased from Sigma-Aldrich (St. Louis, USA) and dissolved in dimethyl sulfoxide (DMSO). DMSO was used as a negative control for all experiments and the concentration of DMSO in media did not exceed $0.1 \%$ (vol/vol), which did not affect the antibiofilm or antivirulence activities. Cell growths and turbidities were measured using spectrophotometer (UV-160, Shimadzu, Japan) at $620 \mathrm{~nm}$.

\section{Assays for Biofilm Formation}

Candida biofilms were developed on 96-well polystyrene plates, as previously reported (Lee et al., 2011). Briefly, a 2-day single colony was inoculated into $25 \mathrm{ml}$ of $\mathrm{PDB}$ and incubated overnight at $37^{\circ} \mathrm{C}$. Overnight cultures at an initial turbidity of 0.1 at $600 \mathrm{~nm}$ were then inoculated into PDB (final volume $300 \mu \mathrm{l}$ ) with or without a gingerol or a shogaol, and incubated for $24 \mathrm{~h}$ without shaking at $37^{\circ} \mathrm{C}$. Biofilm cells that adhered to the 96 -well plates were stained with $0.1 \%$ crystal violet (Sigma-Aldrich, St. Louis, USA) for $20 \mathrm{~min}$, washed repeatedly with sterile distilled water, and resuspended in $95 \%$ ethanol. Plates were read at $570 \mathrm{~nm}$ and results are presented as the averages of at least six repetitions.

\section{Confocal Laser Scanning Microscopy Assay of Biofilm Formation}

C. albicans biofilms were grown on 96-well plates with or without 6-gingerol or 6-shogaol without shaking for $24 \mathrm{~h}$. Planktonic cells were then removed by washing with water three times, and biofilms were stained with carboxyfluorescein diacetate succinimidyl ester (a minimally fluorescent lipophile; Invitrogen, Molecular Probes, Inc, Eugene, USA) (Lee et al., 2016). Plate bases were then visualized using an (a $488 \mathrm{~nm}$ ) Ar laser (emission 500 to $550 \mathrm{~nm}$ ) under a confocal laser microscope (Nikon Eclipse Ti, Tokyo), and COMSTAT biofilm software (Heydorn et al., 2000) was then used to calculate biovolumes $\left(\mu \mathrm{m}^{3} \mu \mathrm{m}^{-2}\right)$, mean biofilm thicknesses $(\mu \mathrm{m})$, and substratum coverages (\%). Two independent cultures were performed under each experimental condition and at least 10 random positions were assayed.

\section{Observation of C. albicans Colony Morphologies on Solid Media}

A freshly prepared glycerol stock of C. albicans was used to streak on PDA plates supplemented with and without 6-gingerol or 6-shogaol. Plates were then incubated for 7 days at $37^{\circ} \mathrm{C}$ and temporal changes in colony morphologies were observed using an iRiS ${ }^{\mathrm{TM}}$ Digital Cell Imaging System (Logos Bio Systems, Korea).

\section{Hyphal Assay in Liquid Media}

Cell aggregation was analyzed as previously described (Zelante et al., 2012). Briefly, C. albicans cells were inoculated into $2 \mathrm{ml}$ of PDB medium or RPMI-1640 medium at density of $10^{5} \mathrm{CFU} / \mathrm{ml}$ in $14 \mathrm{ml}$ test tubes with or without 6-gingerol or 6-shogaol and incubated at $37^{\circ} \mathrm{C}$ for $24 \mathrm{~h}$ with shaking at $250 \mathrm{rpm}$. Cell cultures $(2 \mathrm{ml})$ were then transferred into glass-bottom dishes and observed. Aggregated cells were visualized in bright field using the iRiS ${ }^{\mathrm{TM}}$ Digital Cell Imaging System (Logos Bio Systems, Korea) at a magnification of $4 x$. At least, four independent experiments were conducted.

\section{Microscopic Imaging of Hyphal Formation}

Scanning electron microscopy (SEM) was used to observe the morphologies of biofilm cells attached to a nylon membrane, as previously described (Kim et al., 2016b). Briefly, a nylon 
membrane was cut into $0.5 \times 0.5 \mathrm{~cm}$ pieces and placed in 96 well plates containing C. albicans grown with or without 6gingerol or 6-shogaol and incubated for $24 \mathrm{~h}$ at $37^{\circ} \mathrm{C}$. Cells that adhered to the nylon membrane were fixed with glutaraldehyde (2.5\%) and formaldehyde (2\%) for $24 \mathrm{~h}$ and then post-fixed using osmium, dehydrated with an ethanol series (50, 70, 80, 90, 95, and $100 \%$ ), and isoamyl acetate. After critical-point drying, cells were examined and imaged using a S-4100 scanning electron microscope (Hitachi, Japan) at a voltage of $15 \mathrm{kV}$.

\section{RNA Isolation for RNA-Seq and Quantitative Real-Time PCR (qRT-PCR)}

For transcriptomic analyses, $25 \mathrm{ml}$ of C. albicans at an initial turbidity of 0.1 at $\mathrm{OD}_{600}$ was inoculated into $\mathrm{PDB}$ in $250 \mathrm{ml}$ Erlenmeyer flasks and incubated for $4 \mathrm{~h}$ at $37^{\circ} \mathrm{C}$ with agitation $(250 \mathrm{rpm})$ in the presence or absence of 6 -gingerol $(50 \mu \mathrm{g} / \mathrm{ml})$ or 6-shogaol $(10 \mu \mathrm{g} / \mathrm{ml})$. To prevent RNA degradation, RNase inhibitor (RNAlater, Ambion, TX, USA) was added to cells. Total RNA was isolated using a hot acidic phenol method (Amin-ul Mannan et al., 2009), and RNA was purified using a Qiagen RNeasy mini Kit (Valencia, CA, USA).

\section{RNA-Seq and RNA Library Preparation and Sequencing}

For RNA-Seq, a RNA library was constructed using the SMARTer Stranded RNA-Seq Kit (Clontech Laboratories, Inc., USA). Briefly, $2 \mu \mathrm{g}$ of total RNA was incubated with magnetic beads decorated with oligo-dT and then RNAs, other than mRNA, were removed using washing solution. Library production was initiated by the random hybridization of starter/stopper heterodimers to poly(A) RNA bound to the magnetic beads. These starter/stopper heterodimers contained Illumina-compatible linker sequences. A single-tube reverse transcription and ligation reaction extended the starter to the next hybridized heterodimer, where the newly-synthesized cDNA insert was ligated to the stopper. Second strand synthesis was performed to release the library from the beads, and the library was then amplified. Barcodes were introduced when the library was amplified. High-throughput sequencing was performed by paired-end 100 sequencing using HiSeq 2500 (Illumina, Inc., USA).

\section{RNA-Seq Data Analysis}

mRNA-Seq reads were mapped using TopHat software (Trapnell et al., 2009) in order to obtain the alignment file. Differentially expressed genes were identified based on counts from unique and multiple alignments using Bedtools (Quinlan and Hall, 2010). RT (Read Count) data were processed by Quantile normalization using Bioconductor (Gentleman et al., 2004). The alignment files also were used to assemble transcripts, estimate their abundances, and to detect the differential expressions of genes or isoforms using Cufflinks. FPKM (fragments per kilobase of exon per million fragments) was used to determine the expression levels of gene regions. Gene classification was based on the results of searches performed using DAVID (http:// david.abcc.ncifcrf.gov/). The RNA-seq data were deposited at NCBI Gene Expression Omnibus and are accessible through accession number GSE117201. Differentially expressed gene study was analyzed with the DEG analysis method in ExDEGA (Excel based Differentially Expressed Gene Analysis) tool and classified by biological processes. Gene ontology analysis was performed at QuickGO (www.ebi.ac.uk/QuickGO/). KEGG (Kyoto Encyclopedia of Genes and Genomes) pathway analyses of the RNA-seq data were performed with the KEGG Mapper tool (http://www.genome.jp/kegg/tool/map_pathway2.html).

\section{qRT-PCR}

qRT-PCR was used to determine the expressions of hyphaerelated genes (ALS1, ALS3, ECE1, ECM38, EED1 EFG1, HYR1, $H W P 1, R B T 1, S A P 4$, and UME6). The specific primers and housekeeping gene $(R D N 18)$ used for qRT-PCR are listed in Supplementary Table S2. The qRT-PCR method used was as described by Kim et al. (2016b), and performed using SYBR Green master mix (Applied Biosystems, Foster City, USA) and an ABI StepOne Real-Time PCR System (Applied Biosystems). At least two independent cultures were used.

\section{Antivirulence and Toxicity Assays Using the Caenorhabditis elegans Model}

For the antivirulence assay, we used C. elegans strain fer-15 (b26); fem-1 (hc17), as previously described (Manoharan et al., 2017a). Briefly, synchronized adult worms were fed on C. albicans lawns for $4 \mathrm{~h}$ at $25^{\circ} \mathrm{C}$ and then collected after washing three times with M9 buffer. Approximately 30 worms were then added to each well of 96-well plates containing PDB medium $(300 \mu \mathrm{l})$ with or without 6 -gingerol $(10$ or $50 \mu \mathrm{g} / \mathrm{ml}$ ) or 6 -shogaol (10 or $50 \mu \mathrm{g} / \mathrm{ml}$ ). Assay plates were then incubated for 4 days at $25^{\circ} \mathrm{C}$ without shaking. For toxicity assays, 30 non-infected worms were pipetted into single wells of a 96-well dish containing M9 buffer and solutions of 6-gingerol or 6-shogaol were added to final concentrations of $(0,100,200$, or $500 \mu \mathrm{g} / \mathrm{ml})$ without $C$. albicans. Plates were then incubated for 4 days at $25^{\circ} \mathrm{C}$ without shaking. Three independent experiments were performed in triplicate. Results are expressed as percentages of live worms (survival), as determined by responses to platinum wire touching after incubation for 4 days. Observations were made using an $\mathrm{iRiS}^{\mathrm{TM}}$ Digital Cell Imaging System (Logos Bio Systems, Korea).

\section{Statistical Analysis}

Replication numbers for assays are provided above and results are expressed as means \pm standard deviations. The statistical analysis was performed by one-way ANOVA followed by Dunnett's test using SPSS version 23 (SPSS Inc., Chicago, IL, USA). $P$-values of $<0.05$ were regarded significant.

\section{RESULTS}

\section{Inhibitory Effects of Gingerols and Shogaols on C. albicans Biofilm Formation} Initially, we investigated whether three gingerols (6-gingerol, 8-gingerol, and 10-gingerol) and three shogaols (6-shogaol, 8shogaol, and 10-shogaol) affect biofilm formation by fluconazoleresistant C. albicans DAY185, cell growth was also measured 
in the presence of these agents. Of the six compounds, 6gingerol, 8-gingerol, and 6-shogaol significantly reduced biofilm formation at concentrations of 10,50 , and $100 \mu \mathrm{g} / \mathrm{ml}$, while $10-$ gingerol, 8-shogaol, and 10-shogaol at $100 \mu \mathrm{g} / \mathrm{ml}$ had no effect (Figure 1). In particular, 6-shogaol most significantly inhibited biofilm formation in a dose-dependent manner (Figure 1D). Specifically, 6-shogaol inhibited biofilm formation by 85,94 , and $94 \%$ at concentrations of 10,50 , and $100 \mu \mathrm{g} / \mathrm{ml}$, respectively (Figure 1D). In addition, 6-gingerol and 8-gingerol at $50 \mu \mathrm{g} / \mathrm{ml}$ inhibited biofilm formation by 88 and $80 \%$, respectively (Figures 1A,B). It appeared the antibiofilm activities of gingerols and shogaols were related to the number of carbon side chains as larger carbon side chain numbers appeared to decrease antibiofilm activity in 10-gingerol, 8-shogaol, and 10-shogaol (Figures 1C,E,F). Notably, none of the three gingerols or three shogaols at concentrations up to $100 \mu \mathrm{g} / \mathrm{ml}$ inhibited the planktonic cell growth of C. albicans (Figures 1A-F).

The antifungal activities of 6-gingerol and 6-shogaol were investigated by measuring minimum inhibitory concentrations (MIC), and for 6-gingerol and 6-shogaol MICs were $1000 \mu \mathrm{g} / \mathrm{ml}$ and $>2000 \mu \mathrm{g} / \mathrm{ml}$, respectively, against C. albicans DAY185. These results support the notion that biofilm formation by $C$. albicans was effectively inhibited by the antibiofilm activities of 6-gingerol and 6-shogaol and not by their fungicidal activities. Furthermore, the observed biofilm inhibition in the absence of any effect on planktonic cell growth suggests that unlike conventional fungicides, 6-gingerol and 6-shogaol may less prone to the development of drug resistance.
Confocal laser microscope images showed that C. albicans formed dense biofilms in non-treated control samples, and that in the presence of 6-gingerol or 6-shogaol biofilm cellular densities and thicknesses were dramatically reduced (Figure 2A). Biofilm reduction was further confirmed by COMSTAT analysis, which showed 6-gingerol at $50 \mu \mathrm{g} / \mathrm{ml}$ and 6-shogaol at $10 \mu \mathrm{g} / \mathrm{ml}$ significantly reduced biofilm biomass, average thickness, and substrate coverage (Figure 2B). Specifically, biofilm biomass, thickness, and substrate coverage were reduced by 6 -shogaol by more than $95 \%$ vs. the untreated control.

\section{6-Gingerol and 6-Shogaol Inhibited Hyphal Growth and Cell Aggregation}

To examine the effects of 6-gingerol and 6-shogaol on C. albicans morphology, a temporal observation of C. albicans colonies on potato dextrose agar (PDA) was performed and scanning electron microscope (SEM) was also used. Whereas hyphal protrusions from colonies of untreated $C$. albicans were observed after 3 days of incubation, in the presence of 6shogaol at $10 \mu \mathrm{g} / \mathrm{ml}$ suppressed hyphal protrusions for 7 days (Figure 3A). Furthermore, 6-shogaol at $10 \mu \mathrm{g} / \mathrm{ml}$ was found to more effectively suppress hyphal protrusions than 6-gingerol at $50 \mu \mathrm{g} / \mathrm{ml}$. SEM analysis also confirmed 6-gingerol and 6shogaol substantially suppressed hyphal formation. As shown in Figure 3B, non-treated biofilms consisted predominately of hyphae and few pseudohyphae, where biofilms grown in the presence of 6-gingerol or 6-shogaol had shorter hyphae and more yeast cells.
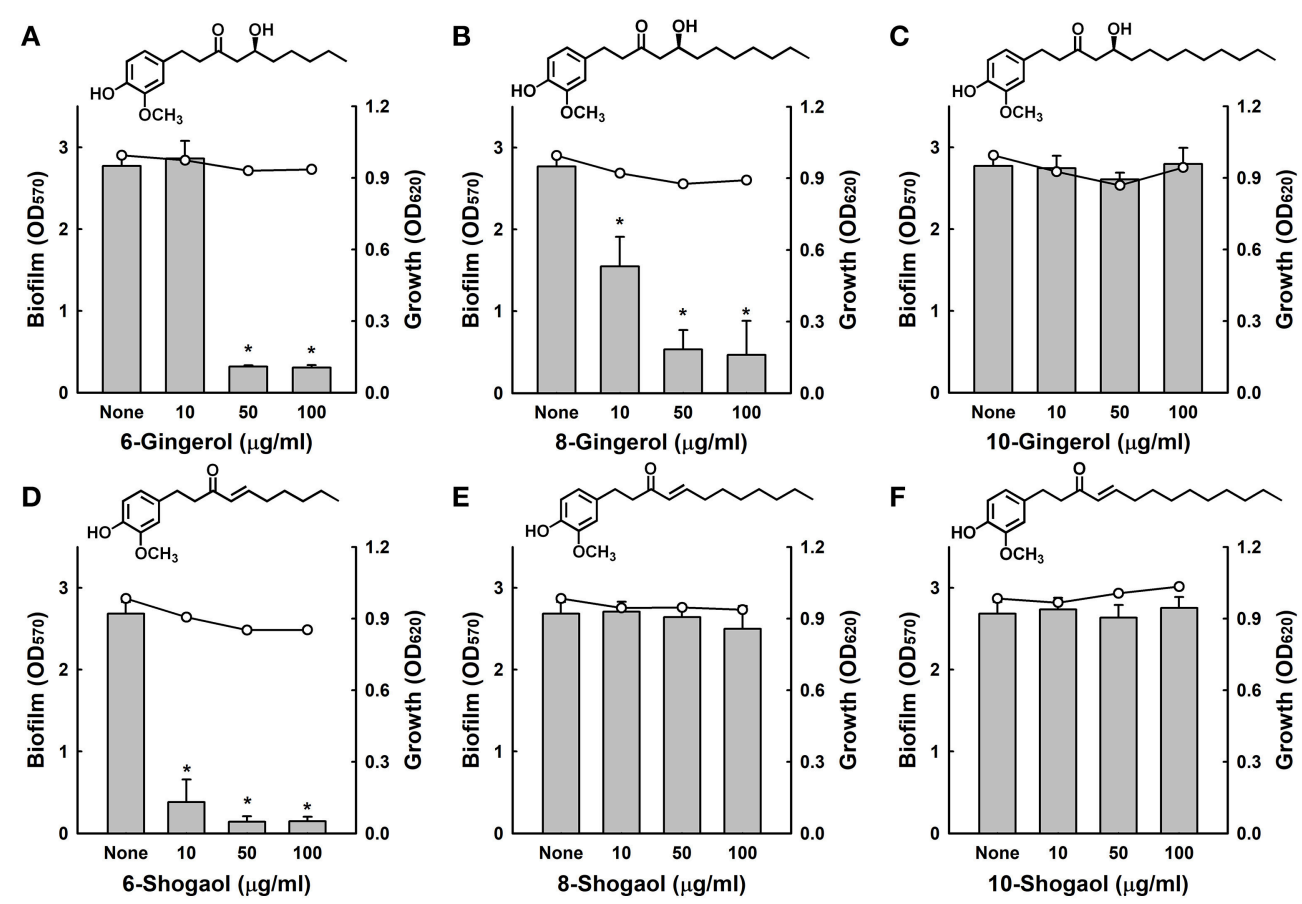

FIGURE 1 | Antibiofilm activities of gingerols and shogaols against C. albicans. The antibiofilm activities of three gingerols (A-C) and three shogaols (D-F) against C. albicans DAY185 in PDB medium were determined after culture for $24 \mathrm{~h}$. Bars indicate biofilm formation and lines indicate planktonic cell growth. The chemical structures of gingerols and shogaols are shown. ${ }^{\star} P<0.05$ vs. non-treated controls. None; non-treated control. 
It is generally believed yeast-to-hypha-transition and cell aggregation are prerequisites of biofilm development by C. albicans (Chandra et al., 2001). In liquid potato dextrose broth (PDB) medium, hyphal inhibition was evident in the presence of 6-gingerol or 6-shogaol and more marked in the presence of 6-shogaol (Figure 4A). Another hyphal assay was performed using RPMI-1640 medium, which promotes hyphal formation (Kucharikova et al., 2011). After incubation for $24 \mathrm{~h}$, mostly hyphae and large cell aggregations entangled by hyphae were observed in the control sample whereas treatment with 6-gingerol or 6-shogaol resulted in much smaller cell aggregations in a dose-dependent manner (Figure 4B). Furthermore, hyphal and cell aggregation results were in-line with the observed antibiofilm activities of 6-gingerol and 6-shogaol. Taken together, these results show 6-gingerol and 6-shogaol both potently inhibited hyphal formation and cell aggregation, and thus, suggest these two agents reduced biofilm formation by C. albicans.

\section{Differential Gene Expressions by 6-gingerol and 6-shogaol}

The molecular bases of the effects of 6-gingerol or 6-shogaol on biofilm formation and hyphal growth were investigated by RNA-seq and qRT-PCR. RNA-seq was first used to determine differential gene expressions in untreated sample and treated samples. Genes differentially expressed by at least 2 -fold were selected and sorted into four functional categories including biofilm and hyphae-related genes or virulence-related genes (Supplementary Table S1). Overall, expression trends were similar after treatment with 6-gingerol at $50 \mu \mathrm{g} / \mathrm{ml}$ or 6 -shogaol at $10 \mu \mathrm{g} / \mathrm{ml}$. However, in view of the concentrations used 6shogaol clearly had a greater effect than 6 -gingerol. The addition of 6-gingerol significantly altered the expressions of 125 genes by more than 2-fold; 37 genes were up-regulated and 88 genes were down-regulated. Similarly, the addition of 6-shogaol significantly altered the expressions of 78 genes; 29 genes were up-regulated and 49 genes were down-regulated.

Notably, these expressional changes involved various biofilmand hypha-related genes (Supplementary Table S1). Specifically, HWP1 (hyphal cell wall protein, also known as ECE2) and ECE1 (hypha-specific protein) were repressed by 6-gingerol or 6-shogaol by more than 7- and 2-fold, respectively, and CDR1 and CDR2 (multidrug transporter) and RTA3 (lipid-translocating exporter) were up-regulated by 6-gingerol or 6-shogaol more than 4-fold. qRT-PCR was used to confirm gene expressional changes of highly differentially expressed loci in the 6-gingerol and 6-shogaol RNA-seq experiments. qRT-PCR for 15 selected genes showed differential changes in expression that generally concurred with RNA-seq assay results (Figure 5). For 6-shogaol experiment, RNA-seq and qRT-PCR showed the genes were repressed to similar extents, i.e., 10-fold vs. 20-fold for CDR1, 3fold vs. 2-fold for CHT2, 12-fold vs. 9-fold for HWP1, 6-fold vs. 9fold for RTA3, respectively. Similarly, 6-gingerol down-regulated the expression of HWP1 and CHT2, and upregulated CDR1 and RTA3. Nevertheless, the expressions of other biofilm and hyphaerelated genes (ALS1, ALS3, EFG1, HYR, PDR16, RBT1, SNQ2,
TEC1, and UME6) were unaffected by 6-gingerol or 6-shogaol. Taken together, RNA-seq and qRT-PCR results showed that 6gingerol and 6-shogaol significantly altered the expressions of some hypha-specific (HWP1 and ECE1), biofilm-related (HWP1 and $R T A 3)$ and multidrug transporter (CDR1 and $C D R 2)$ related genes.

\section{6-Gingerol and 6-Shogaol Rescued Nematodes Infected With C. albicans}

We examined whether 6-gingerol or 6-shogaol could affect C. albicans virulence in a Caenorhabditis elegans nematode model, which is an accepted alternative to mammalian models (Tampakakis et al., 2008). C. albicans infection caused 45\% C. elegans fatality in 4 days. However, $>80 \%$ of nematodes survived in the presence of 6-gingerol or 6-shogaol at $50 \mu \mathrm{g} / \mathrm{ml}$ (Figures 6A,B). To investigate the chemical toxicities of 6gingerol and 6-shogaol, non-infected nematodes were exposed to different concentrations of the two agents. We found 6gingerol and 6-shogaol at concentrations up to $500 \mu \mathrm{g} / \mathrm{ml}$ were not toxic to $C$. elegans (Figure 6C). These results show that both 6-gingerol and 6-shogaol effectively promoted the survival of infected nematodes and that they had no toxic effects on the nematode.

\section{DISCUSSION}

Current study shows for the first time that the ginger components 6-gingerol and 6-shogaol reduce biofilm formation by a drugresistant C. albicans strain by inhibiting hyphae growth and cell aggregation, and reduced fungal virulence.

Ginger (Zingiber officinale (L.) Rosc) has been used as a spice and herbal medicine for over 2000 years. Its roots and extracts contain polyphenol compounds, such as, gingerols, shogaols, paradols, gingerdiols, and zingerone, which have considerable antioxidant activity ( $\mathrm{Si}$ et al., 2018). Fresh ginger contains about $4 \%$ of 6 -gingerol by weight but almost no 6shogaol. However, 6-shogaol is easily produced by dehydrating 6-gingerol using drying processes (Chen et al., 1986; Jolad et al., 2004). 6-Gingerol and 6-shogaol have been reported to be effective treatments for metabolic syndrome, cardiovascular disease, dementia, arthritis, diabetes, osteoporosis, cancers, and infectious diseases (Ali et al., 2008; Kim et al., 2010). The antibacterial activities of gingerols and shogaols have been also studied (Park et al., 2008). More recently, the antibiofilm activities of 6-gingerol (Kim et al., 2015) and 6- and 8-gingerol analogs (Choi et al., 2017) against P. aeruginosa have been reported. Interestingly, 6-gingerol inhibited biofilm formation of both $P$. aeruginosa (Kim et al., 2015) (Choi et al., 2017) and C. albicans without affecting the planktonic cell growth and showed no chemical toxicity. 6-Gingerol including its analogs interfere the quorum sensing system in $P$. aeruginosa, while 6-gingerol and 6-shogaol suppressed hyphal growth in this study.

Of the six gingerol and shogaol compounds studied in the present study, 6-gingerol and 6-shogaol most effectively reduced C. albicans biofilm formation (Figure 1) and 6-shogaol most 
A

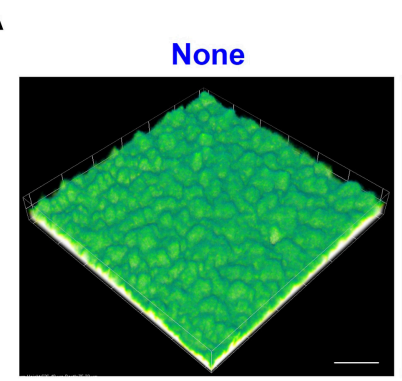

B

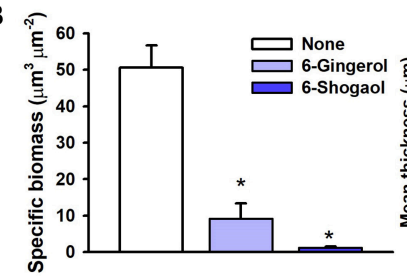

\section{6-Gingerol}

(50 $\mu \mathrm{g} / \mathrm{ml})$
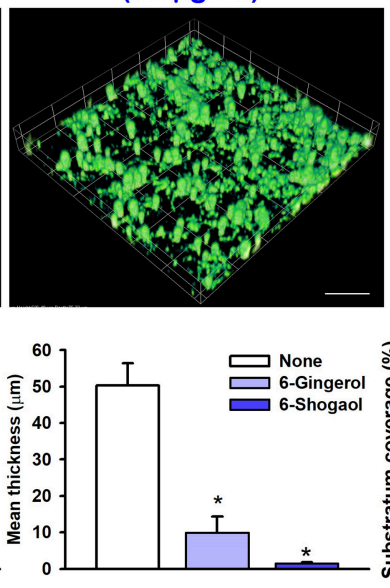

6-Shogaol

$(10 \mu \mathrm{g} / \mathrm{ml})$
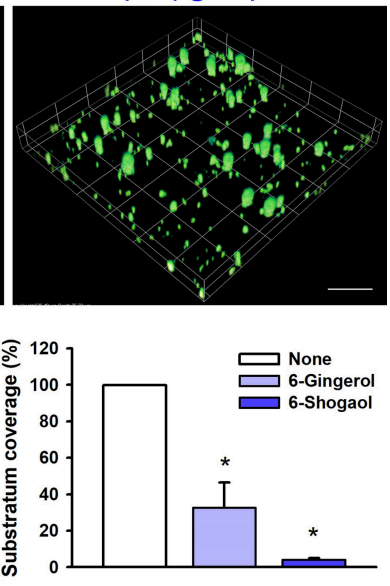

FIGURE 2 | Microscopic observations of the inhibitory effects of 6-gingerol and 6-shogaol on biofilms. Biofilm formation by C. albicans on polystyrene plates was observed in the presence of 6-gingerol at $50 \mu \mathrm{g} / \mathrm{ml}$ or 6 -shogaol at $10 \mu \mathrm{g} / \mathrm{ml}$ by confocal laser microscopy (A). Scale bars represent $100 \mu \mathrm{m}$. Biofilm formation was quantified by using COMSTAT (B). ${ }^{*} P<0.05$ vs. non-treated controls. None; non-treated control.

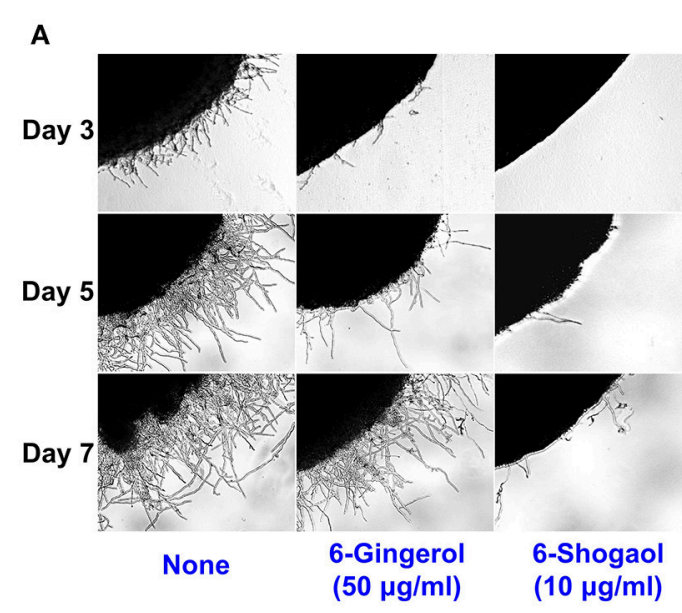

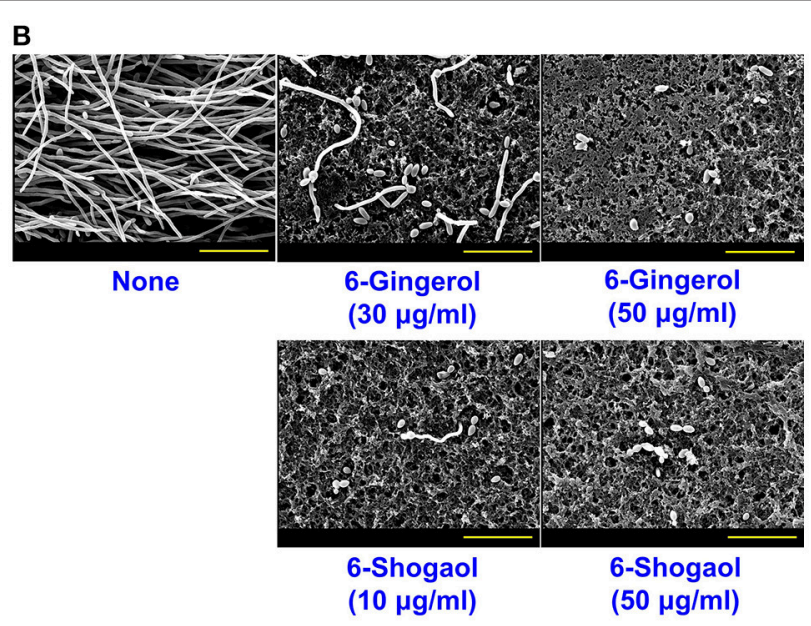

FIGURE 3 | Effects of 6-gingerol and 6-shogaol on the hyphal morphogenesis of C. albicans. C. albicans morphology on solid media (A). C. albicans was streaked on PDA solid plates in the absence or presence of 6-gingerol or 6-shogaol. Colony morphologies were observed during incubation for 7 days at $37^{\circ} \mathrm{C}$. Inhibitions of hyphal growths by 6-gingerol or 6-shogaol in C. albicans biofilms were visualized by SEM (B). The scale bar represents $30 \mu \mathrm{m}$. None; non-treated control.

inhibited biofilm formation, hyphae growth, cell aggregation, and fungal virulence (Figures 1-5). It has been reported on several occasions that the biological potency of 6-shogaol is greater than that of 6-gingerol, and interestingly, these compounds differ structurally by the presence of a hydroxyl moiety in 6gingerol and double bond on the carbon side chain of 6-shogaol (Figures 1A,D). The presence of this hydroxyl moiety has been previously reported to importantly influence proinflammatory gene activation (Isa et al., 2008). Furthermore, 6-shogaol has been reported to have a markedly stronger anti-tumorigenic effect than 6-gingerol (Wu et al., 2010). Previous studies have suggested a,b-unsaturated carbonyls are susceptible to nucleophilic addition reactions with thiols, such as, glutathione, the most abundant nonprotein thiol in vivo (Boyland and Chasseaud, 1968). The transcriptomic analysis conducted in the present study showed 6-gingerol at $50 \mu \mathrm{g} / \mathrm{ml}$ resulted in similar changes in global gene expression as those induced by 6 shogaol at $10 \mu \mathrm{g} / \mathrm{ml}$ (Figure 5), which indicates 6-gingerol and 6 -shogaol act at the transcriptional level. We suggest that the structural difference between 6-gingerol and 6-shogaol influence the abilities of these to influence the expressions of hyphaeregulatory genes in the hyphae signaling pathway. Also, we have observed the antibiofilm and antihyphae activities of 8gingerol (Supplementary Figures S1, S2) and the action mode of 


\section{a PDB medium}
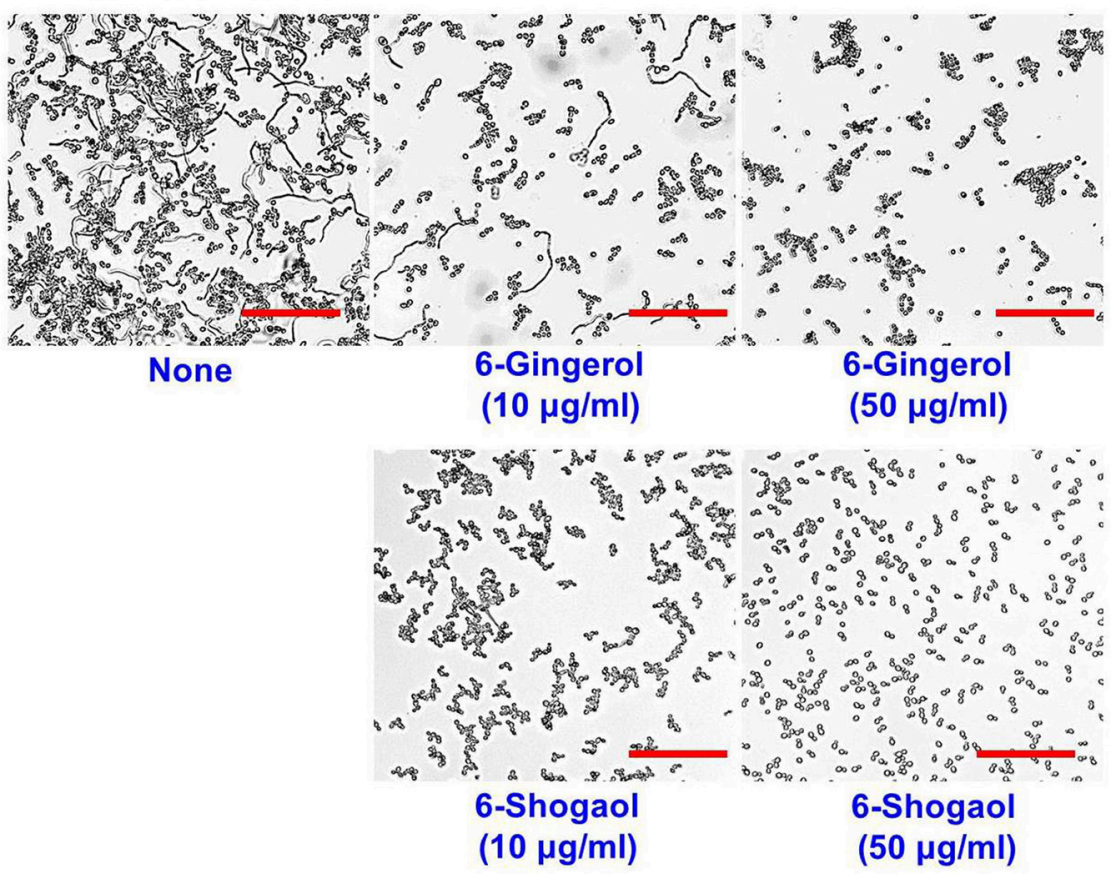

B RPMI-1640 medium

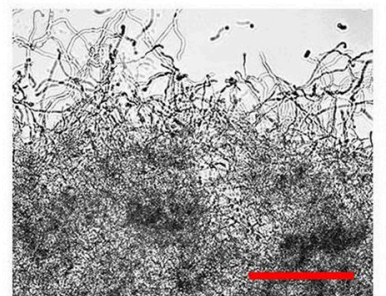

None

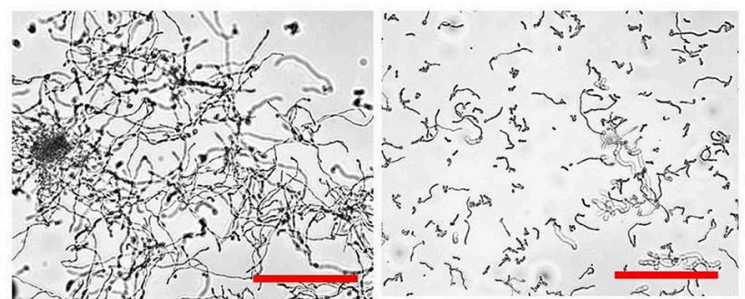

6-Gingerol

$(10 \mu \mathrm{g} / \mathrm{ml})$

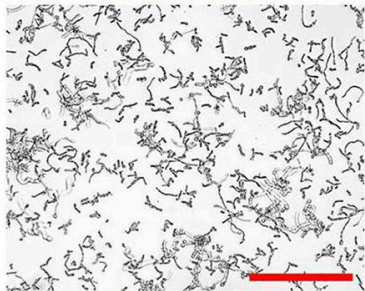

6-Shogaol

$(10 \mu \mathrm{g} / \mathrm{ml})$
6-Gingerol

$(50 \mu \mathrm{g} / \mathrm{ml})$

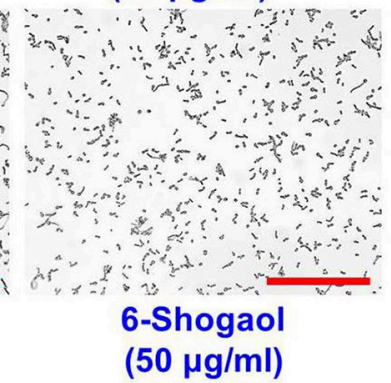

FIGURE 4 | Inhibitions of hyphal filamentation and aggregation by 6-gingerol and 6-shogaol in liquid medium. Inhibitions of hyphal filamentation in PDB medium (A) and in RPMI medium (B). C. albicans cells were grown for $24 \mathrm{~h}$ in PDB medium or RPMI-1640 medium in the absence or presence of 6-gingerol or 6-shogaol. Hyphae were visualized after incubation for $24 \mathrm{~h}$. The scale bar represents $200 \mu \mathrm{m}$. None; non-treated control.

8-gingerol is probably similar to that of 6-gingerol and 6-shogaol in C. albicans.

In the present study, we found the transcriptional levels of several hyphae-specific and biofilm-related genes were significantly altered by 6-gingerol and by 6-shogaol (Supplementary Table S1). Gene ontology analysis showed that 6-ginerol and 6-shogaol regulated expression of genes involving membrane components, transport proteins, pathogenesis, stress, and biofilm formation (Supplementary Figure S3). KEGG analysis showed that 6-ginerol and 6-shogaol are similarly associated with several metabolisms such as glycerophospholipid, meiosis, ABC transport, and carbon 


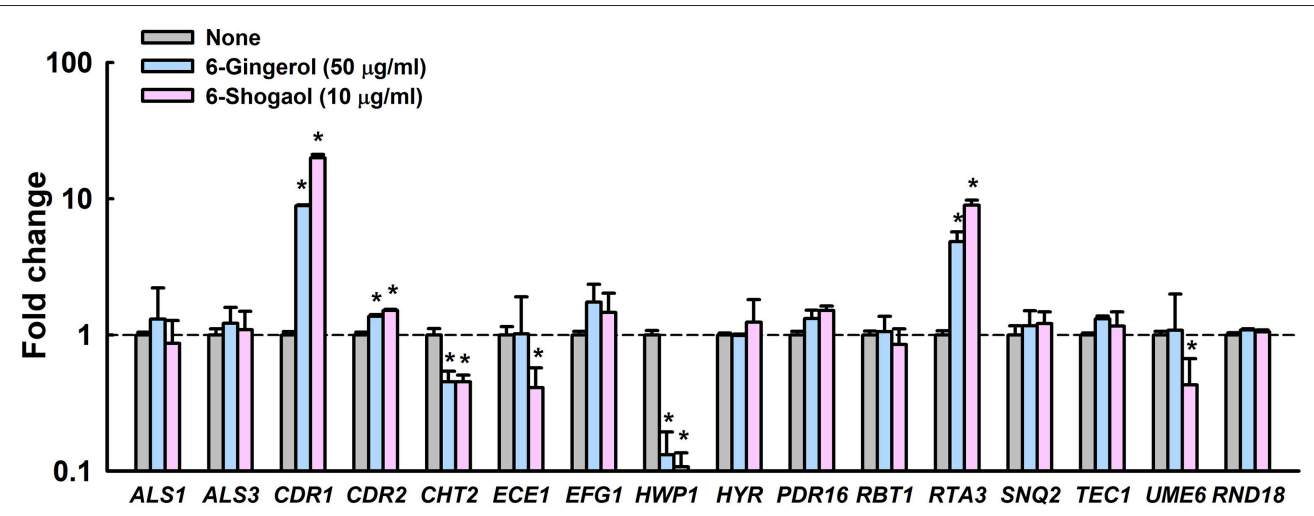

FIGURE 5 | Transcriptional profiles of C. albicans cells treated with or without 6-gingerol or 6-shogaol. C. albicans was cultivated with or without 6-gingerol at $50 \mu \mathrm{g} / \mathrm{ml}$ or 6 -shogaol at $10 \mu \mathrm{g} / \mathrm{ml}$ for $4 \mathrm{~h}$ with shaking at $250 \mathrm{rpm}$. Transcriptional profiles were obtained by qRT-PCR. Fold changes represent changes in the transcriptions of treated vs. untreated $C$. albicans. The experiment was performed in duplicate (six qRT-PCR reactions were performed per gene). ${ }^{\star} P<0.05$ vs. non-treated controls (None).
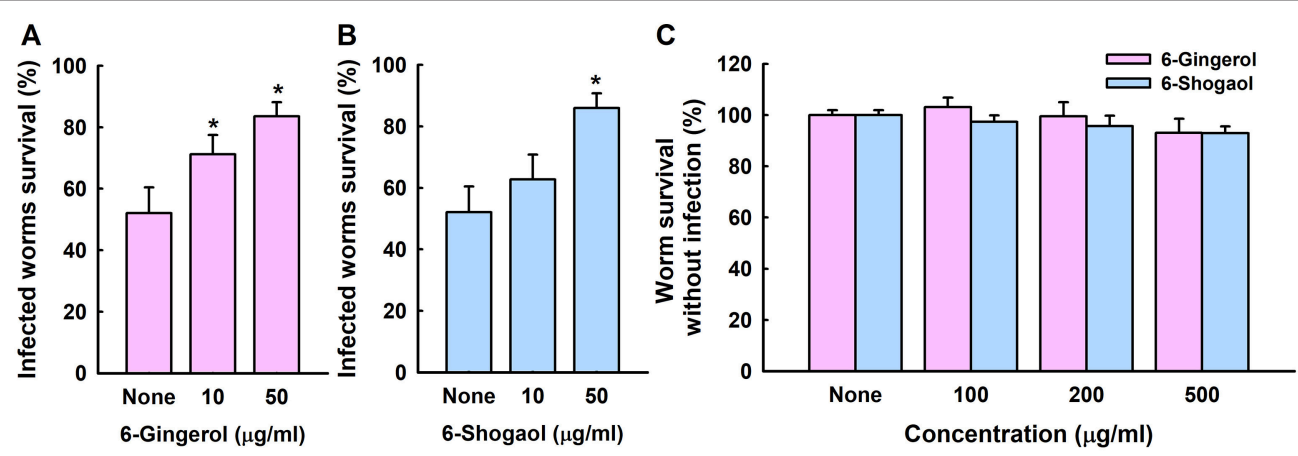

FIGURE 6 | Effects of 6-gingerol and 6-shogaol on C. albicans infected C. elegans. Nematode survival after exposure to C. albicans for 4 days in the presence of 6-gingerol (A) or 6-shogaol (B). The toxicities of 6-gingerol and 6-shogaol were determined by treating non-infected nematodes for 4 days (C). None indicates non-treated controls. Worm survival was determined based on movement. ${ }^{*} p<0.05$ vs. non-treated controls.

metabolism (Supplementary Figure S4). Most noticeably, HWP1 and ECE1 were down-regulated, and ECE1 is essential for hyphal development and its expression has been shown to be correlated with cell elongation and biofilm formation (Nobile et al., 2006a). The down-regulations of HWP1 and ECE1 by 6-gingerol or 6-shogaol are consistent with their observed effects on biofilm formation and hyphal development. HWP1 encodes a hyphal wall protein that is essential for hyphal development (Nobile et al., 2006b) and intercellular adherence (Orsi et al., 2014). Previously, we reported that camphor and fenchyl alcohol from cedar leaf oil (Manoharan et al., 2017b) and alizarin from the roots of the madder genus (Manoharan et al., 2017a) inhibit C. albicans biofilm formation by reducing hyphal formation by suppressing the gene expressions of HWP1 and ECE1. Thus, it appears that the ability to reduce hyphal formation is not rare in the plant kingdom and that this offers a practical means of inhibiting biofilm formation by C. albicans.

On the other hand, both 6-gingerol and 6-shogaol upregulated the expressions of CDR1 (Candida drug resistance, multidrug transporter) and RTA3 (lipid-translocating exporter) about 10-fold. CDR1 is a major ABC transporter, and in a previous study, CDR1 mRNA levels were found to be positively correlated with an increase in azole resistance in C. albicans isolates and to be up-regulated during biofilm formation (White, 1997). Ramage et al. reported CDR1 mutant was highly susceptible to fluconazole when growing planktonically but retained the resistant phenotype during biofilm growth (Ramage et al., 2002). On the other hand, the RTA3 gene encodes Rta1 p-like lipidtranslocating exporter and its expression was found to be positively associated with CDR1 expression (Whaley et al., 2016). Hence, it is possible that C. albicans strives to pump out 6gingerol and 6-shogaol, which might increase azole-resistance in C. albicans when azole antifungal agent(s) and 6-gingerol or 6-shogaol are co-administrated.

The emergence of multidrug resistant Candida strains has driven investigations on alternative antifungal agents, and antivirulence and antibiofilm agents have attracted considerable research interest. The present study shows that the antibiofilm effects of 6-gingerol and 6-shogaol on fluconazole-resistant C. albicans DAY185 are due to the prevention of yeast-hyphal 
transition and not to the inhibition of fungal growth. Also, 6gingerol and 6-shogaol effectively reduced C. albicans virulence in vivo in a Caenorhabditis elegans model with minimal chemical toxicity under the conditions used. In conclusion, 6-gingerol and 6-shogaol have the antibiofilm and antivirulence activities against a drug resistant $C$. albicans.

\section{AUTHOR CONTRIBUTIONS}

J-HL, Y-GK, JGP, and JL designed research, performed experiments, and analyzed the data. PC, JH, and JGP provided materials. J-HL and JL wrote the manuscript. All authors read and approved the final manuscript.

\section{REFERENCES}

Ali, B. H., Blunden, G., Tanira, M. O., and Nemmar, A. (2008). Some phytochemical, pharmacological and toxicological properties of ginger (Zingiber officinale Roscoe): a review of recent research. Food Chem. Toxicol. 46, 409-420. doi: 10.1016/j.fct.2007.09.085

Amin-ul Mannan, M., Sharma, S., and Ganesan, K. (2009). Total RNA isolation from recalcitrant yeast cells. Anal. Biochem. 389, 77-79. doi: 10.1016/j.ab.2009.03.014

Boyland, E., and Chasseaud, L. F. (1968). Enzymes catalysing conjugations of glutathione with alpha-beta-unsaturated carbonyl compounds. Biochem. J. 109, 651-661. doi: 10.1042/bj1090651

Carradori, S., Chimenti, P., Fazzari, M., Granese, A., and Angiolella, L. (2016). Antimicrobial activity, synergism and inhibition of germ tube formation by Crocus sativus-derived compounds against Candida spp. J. Enzyme Inhib. Med. Chem. 31, 189-193. doi: 10.1080/14756366.2016.1180596

Chandra, J., Kuhn, D. M., Mukherjee, P. K., Hoyer, L. L., McCormick, T., and Ghannoum, M. A. (2001). Biofilm formation by the fungal pathogen Candida albicans: development, architecture, and drug resistance. J. Bacteriol. 183, 5385-5394. doi: 10.1128/JB.183.18.5385-5394.2001

Chen, C.-C., Rosen, R. T., and Ho, C.-T. (1986). Chromatographic analyses of isomeric shogaol compounds derived from isolated gingerol compounds of ginger (zingiber officinale roscoe). J. Chromatogr. A 360, 175-184. doi: 10.1016/S0021-9673(00)91660-1

Choi, H., Ham, S. Y., Cha, E., Shin, Y., Kim, H. S., Bang, J. K., et al. (2017). Structure-activity relationships of 6-and 8-gingerol analogs as anti-biofilm agents. J. Med. Chem. 60, 9821-9837. doi: 10.1021/acs.jmedchem.7b01426

Gentleman, R. C., Carey, V. J., Bates, D. M., Bolstad, B., Dettling, M., Dudoit, S., et al. (2004). Bioconductor: open software development for computational biology and bioinformatics. Genome Biol. 5:R80. doi: 10.1186/gb-2004-5-10-r80

Heydorn, A., Nielsen, A. T., Hentzer, M., Sternberg, C., Givskov, M., Ersboll, B. K., et al. (2000). Quantification of biofilm structures by the novel computer program COMSTAT. Microbiology 146, 2395-2407. doi: 10.1099/00221287-146-10-2395

Isa, Y., Miyakawa, Y., Yanagisawa, M., Goto, T., Kang, M. S., Kawada, T., et al. (2008). 6-Shogaol and 6-gingerol, the pungent of ginger, inhibit TNF-alpha mediated downregulation of adiponectin expression via different mechanisms in 3T3-L1 adipocytes. Biochem. Biophys. Res. Commun. 373, 429-434. doi: 10.1016/j.bbrc.2008.06.046

Jolad, S. D., Lantz, R. C., Solyom, A. M., Chen, G. J., Bates, R. B., and Timmermann, B. N. (2004). Fresh organically grown ginger (Zingiber officinale): composition and effects on LPS-induced PGE2 production. Phytochemistry 65, 1937-1954. doi: 10.1016/j.phytochem.2004.06.008

Khiralla, G. M. (2015). Antibiofilm and anti-adhesive effects of ginger against some food-related pathogens. J. Food Res. Technol. 3, 87-96.

Kim, H. S., Cha, E., Kim, Y., Jeon, Y. H., Olson, B. H., Byun, Y., et al. (2016a). Raffinose, a plant galactoside, inhibits Pseudomonas aeruginosa biofilm formation via binding to LecA and decreasing cellular cyclic diguanylate levels. Sci. Rep. 6:25318. doi: 10.1038/srep25318

\section{ACKNOWLEDGMENTS}

This research was supported by the Basic Science Research Program through the NRF funded by the Ministry of Education (2018R1D1A3B07040699 to J-HL and 2018R1D1A1B07044288 to JL), and by the Priority Research Centers Program through the NRF funded by the Ministry of Education (2014R1A6A1031189).

\section{SUPPLEMENTARY MATERIAL}

The Supplementary Material for this article can be found online at: https://www.frontiersin.org/articles/10.3389/fcimb. 2018.00299/full\#supplementary-material

Kim, H. S., Lee, S. H., Byun, Y., and Park, H. D. (2015). 6-Gingerol reduces Pseudomonas aeruginosa biofilm formation and virulence via quorum sensing inhibition. Sci. Rep. 5:8656. doi: 10.1038/srep08656

Kim, H. S., and Park, H. D. (2013). Ginger extract inhibits biofilm formation by Pseudomonas aeruginosa PA14. PLoS ONE 8:e76106. doi: 10.1371/journal.pone.0076106

Kim, M. K., Chung, S. W., Kim, D. H., Kim, J. M., Lee, E. K., Kim, J. Y., et al. (2010). Modulation of age-related NF- $\mathrm{B}$ activation by dietary zingerone via MAPK pathway. Exp. Gerontol. 45, 419-426. doi: 10.1016/j.exger.2010.03.005

Kim, Y.-G., Lee, J.-H., Gwon, G., Kim, S.-I., Park, J. G., and Lee, J. (2016b). Essential oils and eugenols inhibit biofilm formation and the virulence of Escherichia coli O157:H7. Sci. Rep. 6:36377. doi: 10.1038/srep36377

Kucharikova, S., Tournu, H., Lagrou, K., Van Dijck, P., and Bujdakova, H. (2011). Detailed comparison of Candida albicans and Candida glabrata biofilms under different conditions and their susceptibility to caspofungin and anidulafungin. J. Med. Microbiol. 60, 1261-1269. doi: 10.1099/jmm.0.032037-0

Kumar, L., Chhibber, S., and Harjai, K. (2013). Zingerone inhibit biofilm formation and improve antibiofilm efficacy of ciprofloxacin against Pseudomonas aeruginosa PAO1. Fitoterapia 90, 73-78. doi: 10.1016/j.fitote.2013.06.017

Lee, J.-H., Cho, M. H., and Lee, J. (2011). 3-Indolylacetonitrile decreases Escherichia coli O157:H7 biofilm formation and Pseudomonas aeruginosa virulence. Environ. Microbiol. 13, 62-73. doi: 10.1111/j.1462-2920.2010.02308.x

Lee, J.-H., Kim, Y.-G., Ryu, S. Y., and Lee, J. (2016). Calcium-chelating alizarin and other anthraquinones inhibit biofilm formation and the hemolytic activity of Staphylococcus aureus. Sci. Rep. 6:19267. doi: 10.1038/srep19267

Manoharan, R. K., Lee, J.-H., Kim, Y.-G., and Lee, J. (2017a). Alizarin and chrysazin inhibit biofilm and hyphal formation by Candida albicans. Front. Cell. Infect. Microbiol. 7:447. doi: 10.3389/fcimb.2017.00447

Manoharan, R. K., Lee, J.-H., and Lee, J. (2017b). Antibiofilm and antihyphal activities of cedar leaf essential oil, camphor, and fenchone derivatives against Candida albicans. Front. Microbiol. 8:1476. doi: 10.3389/fmicb.2017.01476

Nascimento, G. G. F., Locatelli, J., Freitas, P. C., and Silva, G. L. (2000). Antibacterial activity of plant extracts and phytochemicals on antibiotic-resistant bacteria. Braz. J. Microbiol. $\quad 31, \quad 247-256$. doi: 10.1590/S1517-838220000004 00003

Nobile, C. J., Andes, D. R., Nett, J. E., Smith, F. J., Yue, F., Phan, Q. T., et al. (2006a). Critical role of Bcr1-dependent adhesins in C. albicans biofilm formation in vitro and in vivo. PLoS Pathog. 2:e63. doi: 10.1371/journal.ppat.0020063

Nobile, C. J., Nett, J. E., Andes, D. R., and Mitchell, A. P. (2006b). Function of Candida albicans adhesin Hwp1 in biofilm formation. Eukaryot. Cell 5, 1604-1610. doi: 10.1128/EC.00194-06

Orsi, C. F., Borghi, E., Colombari, B., Neglia, R. G., Quaglino, D., Ardizzoni, A., et al. (2014). Impact of Candida albicans hyphal wall protein 1 (HWP1) genotype on biofilm production and fungal susceptibility to microglial cells. Microb. Pathog. 69-70, 20-27. doi: 10.1016/j.micpath.2014.03.003

Park, M., Bae, J., and Lee, D. S. (2008). Antibacterial activity of [10]-gingerol and [12]-gingerol isolated from ginger rhizome against periodontal bacteria. Phytother. Res. 22, 1446-1449. doi: 10.1002/ptr.2473 
Quinlan, A. R., and Hall, I. M. (2010). BEDTools: a flexible suite of utilities for comparing genomic features. Bioinformatics 26, 841-842. doi: 10.1093/bioinformatics/btq033

Ramage, G., Bachmann, S., Patterson, T. F., Wickes, B. L., and Lopez-Ribot, J. L. (2002). Investigation of multidrug efflux pumps in relation to fluconazole resistance in Candida albicans biofilms. J. Antimicrob. Chemother. 49, 973-980. doi: $10.1093 /$ jac/dkf049

Ramage, G., Saville, S. P., Thomas, D. P., and Lopez-Ribot, J. L. (2005). Candida biofilms: an update. Eukaryot. Cell 4, 633-638. doi: 10.1128/EC.4.4.633-638.2005

Sandai, D., Tabana, Y. M., Ouweini, A. E., and Ayodeji, I. O. (2016). Resistance of Candida albicans biofilms to drugs and the host immune system. Jundishapur J. Microbiol. 9:e37385. doi: 10.5812/jjm.37385

Sardi, J. C., Scorzoni, L., Bernardi, T., Fusco-Almeida, A. M., and Mendes Giannini, M. J. (2013). Candida species: current epidemiology, pathogenicity, biofilm formation, natural antifungal products and new therapeutic options. J. Med. Microbiol. 62, 10-24. doi: 10.1099/jmm.0.045054-0

Si, W. H., Chen, Y. P., Zhang, J. H., Chen, Z. Y., and Chung, H. Y. (2018). Antioxidant activities of ginger extract and its constituents toward lipids. Food Chem. 239, 1117-1125. doi: 10.1016/j.foodchem.2017.07.055

Taff, H. T., Mitchell, K. F., Edward, J. A., and Andes, D. R. (2013). Mechanisms of Candida biofilm drug resistance. Future Microbiol. 8, 1325-1337. doi: $10.2217 / \mathrm{fmb} .13 .101$

Tampakakis, E., Okoli, I., and Mylonakis, E. (2008). A C. elegans-based, whole animal, in vivo screen for the identification of antifungal compounds. Nat. Protoc. 3, 1925-1931. doi: 10.1038/nprot.2008.193

Tobudic, S., Lassnigg, A., Kratzer, C., Graninger, W., and Presterl, E. (2010). Antifungal activity of amphotericin B, caspofungin and posaconazole on Candida albicans biofilms in intermediate and mature development phases. Mycoses 53, 208-214. doi: 10.1111/j.1439-0507.2009.01690.x
Trapnell, C., Pachter, L., and Salzberg, S. L. (2009). TopHat: discovering splice junctions with RNA-Seq. Bioinformatics 25, 1105-1111. doi: 10.1093/bioinformatics/btp120

Whaley, S. G., Tsao, S., Weber, S., Zhang, Q., Barker, K. S., Raymond, M., et al. (2016). The RTA3 gene, encoding a putative lipid translocase, influences the susceptibility of Candida albicans to fluconazole. Antimicrob. Agents Chemother. 60, 6060-6066. doi: 10.1128/AAC.00732-16

White, T. C. (1997). Increased mRNA levels of ERG16, CDR, and MDR1 correlate with increases in azole resistance in Candida albicans isolates from a patient infected with human immunodeficiency virus. Antimicrob. Agents Chemother. 41, 1482-1487.

Wu, H., Hsieh, M. C., Lo, C. Y., Bin Liu, C., Sang, S. M., Ho, C. T., et al. (2010). 6-Shogaol is more effective than 6-gingerol and curcumin in inhibiting 12-Otetradecanoylphorbol 13-acetate-induced tumor promotion in mice. Mol. Nutr. Food Res. 54, 1296-1306. doi: 10.1002/mnfr.200900409

Zelante, T., Iannitti, R. G., De Luca, A., Arroyo, J., Blanco, N., Servillo, G., et al. (2012). Sensing of mammalian IL-17A regulates fungal adaptation and virulence. Nat. Commun. 3:683. doi: 10.1038/ncomms1685

Conflict of Interest Statement: The authors declare that the research was conducted in the absence of any commercial or financial relationships that could be construed as a potential conflict of interest.

Copyright (C) 2018 Lee, Kim, Choi, Ham, Park and Lee. This is an open-access article distributed under the terms of the Creative Commons Attribution License (CC BY). The use, distribution or reproduction in other forums is permitted, provided the original author(s) and the copyright owner(s) are credited and that the original publication in this journal is cited, in accordance with accepted academic practice. No use, distribution or reproduction is permitted which does not comply with these terms. 